\title{
ATUALIZAÇÃO
}

\section{PENICILINOTERAPIA EM NEUROLOGIA}

\section{J. M. TAQUES BITTENCOURT *}

A terapêtica das infecções bacterianas era pouco mais que um ideal em 1935. Com o advento do prontozil e o rápido desenvolvimento da terapêutica sulfonamídica, muitos germes foram atacados com êxito. Parecia provável que medicamentos novos dêsse tipo pudessem combater tôdas as infecções. Foi uma esperança malograda e nestes últimos anos a utilização das sulfonamidas tem sido mais restringida que ampliada.

Outra grande descoberta terapêutica, a penicilina, veio reavivar esta esperança: trata-se de substância bacteriostática com quase completa atoxidez, permitindo introduzir no sangue 1.000 vezes a concentração necessária para a ação terapêutica, sem qualquer efeito nocivo; 1 os únicos limites para seu uso são a grande especificidade e a necessidade de economizar remédio tão precioso e de tão difícil obtenção. A penicilina, pertencendo à classe dos antibióticos, se bem seja l:mitada em sua ação pela grande espec:ficidade etiológica, representa um grande avanço sôbre os agentes quimioterápicos conhecidos, por não ser tóxica e, principalmente, por ser capaz de agir nos casos sulfonamido-resistentes. Suas propriedades foram descobertas em 1940, depois de laboriosas pesquisas $2,3,4,5,6,7$, cujas etapas podem ser assim sumarizadas: 1) descoberta de antibióticos ou substâncias antibacterianas de origem natural; 2) descoberta da penicilina por Alexander Fleming; 3) estudos sôbre suas propriedades quimioterápicas; 4) estudos or:entados em três direções, a saber: a)

* Assistente de Clínica Neurológica da Faculdade de Medicina da Universidade de S. Paulo. Assistente do Laboratório Central do Hospital de Clínicas (secção líqüido cefalorraquidiano).

1. Garrod, L. P. - Pen'cilina; suas propriedades e poder como agente terapéutico. Bol. Méd. Brit. 2: 3, 1944.

2. Cintra do Prado, F. - Penincilina, a nova arma antibacteriana. D. D. C. (S. Paulo) 1:173 (julho, agôsto) 1943.

3. Fleming, A. - A descoberta da penicilina. Bol. Med. Brit. 2: 5, 1944.

4. Chain, E. e Florey, H. W. - A descoberta das propriedades quimioterápicas da penicilina. Bol. Méd. Brit. 2: 6, 1944.

5. Fleming, A. - A penicilina para cultura seletiva e para demonstrar inibições bacterianas. Bol. Med. Brit. 2: 8, 1944.

6. Florey, M. E. - Os usos clínicos da penicilina. Bol. Méd. Brit. 2: 11, 1944.

7. Florey, H. W. - Penicillin: a survey. Brit. Med. Jour. 2: 169 (agôsto, 5) 1944. 
produção em massa do medicamento; b) investigação de sua estrutura química e, eventualmente, possibilidade de síntese; c) aplicações clínicas.

Devemos a Pasteur (1877) a primeira observação sôbre antibióticos: a parada no crescimento do $\mathrm{B}$. anthracis pelas bactérias comuns do ar. Depois dêle. Emmerich e Loew estudaram êste fato. chegando a colocar no mercado um medicamento tópico para as úlceras diftéricas e antraz. Em 1928, Fleming descobriu a propriedade do Pen:cillium notatum de impedir o crescimento do estafilococo e estudou o efeito da penic lina, extraída por Clutterbuck, Lovell c Raistrick sôbre o crescimento de muitos germes. Contudo, tanto êstes autores como o próprio Fleming chegaram à conclusão de que a penicilina era uma substância instável, cujo emprêgo prático tinha pouco valor em medicina.

Em 1938, investigadores de Oxford (Florey. Chain, Abraham. Gardner, Heatley: Jennings, Sanders. Fletcher e Lady Florey) estudaram sistemàticamente o novo antibiótico e, após dois anos, puderam ensaiar a penicilina no tratamento de moléstias humanas.

Os primeiros pacientes foram tratados no inverno e primavera de 1940-41, ficando provado o alto poder curativo dêsse medicamento. Seu uso pode ser feito de duas maneiras: 1) geral, injetando-a na veia ou no músculo, donde passa à circulação. E o método obrigatório nas moléstias septicêmicas e naquelas de caráter grave como pneumonia, doenças dos ossos, etc. e quando não se pode fazer chegar o medicamento ao local da infecção. Este método tem o inconveniente de exigir o emprêgo de grandes quantidades de med:camento, pois êle é ràpidamente excretado pelos rins; 2) local, colocando a medicação no ponto onde deve exercer sua ação. A penicilina tem sido utilizada desta maneira nos ferimentos de guerra e no tratamento das inflamações das serosas (meninges, cavidade pleural, articulações e peritôneo). Devemos acres. centar a possibilidade do emprêgo combinado dêstes métodos.

As conclusões clínicas oriundas do emprêgo da penicilina na clínica civil e o conhecimento perfeito de seu valor e de suas limitações estão restringidos pelo pequeno número de observações realizadas, pois a grande dificuldade na sua obtenção limita a produção, que é quase tôda enviada às frentes de combate. Ainda assim, acreditamos que já se possa, atualmente, ter uma idéia relativamente justa sôbre seu valor e emprêgo ${ }^{8,9}$.

\section{PROPRIEDADES QUIMICAS E FARMACODINAMICAS}

A penicilina é um extrato de cultura fluida de Penicillium notatum. Ainda não se esclareceu se se trata de um elemento de desassimilação do fungo ou se é produto de síntese processada no meio de cultura por ação de catalisadores elaborados pelas células do cogumelo. ${ }^{\theta}$

E um ácido de baixo pèso molecular 10 que sòmente se mantém estável enı água na forma de sais entre $\mathrm{pH} 5$ e $\overline{7}$; no meio ácido ou básico é des-

8. Linhares, H. - Da penicilina, numa revisão geral. Imprensa Médica (Rio de Janeiro) 20:43 (julho) 1944.

9. Aragão, R. M. - Penicilina. Estudo terapêutico. Resenha Médica (Rio de Janeiro) 11:3 (julho-setembro) 1944.

10. Abraham, E. P., Chain, E. e Holiday, E. R. - Purification and some physical and chemical properties of penicillin; with a note on the spectrographic examination of penicillin preparation. Brit. J. Exper. Path. 23:103, 1942.

11. Abraham, loc. cit. 10. A atividade bacteriostática da penicilina é 1 eduzida de $80 \%$ em 3 minutos se posta em contacto com ácido clorídrico a $0,2 \mathrm{~N}$ à temperatura de $25^{\circ} \mathrm{C}$. Este fato faz prever a ação inibitória do suco gástrico sôbre a medicação e por conseguinte a impraticabilidade da via oral. 
truída ràpidamente, 11 assim como na presença de certos metais como cobre, cádmio, zinco, mercúrio, dos álcoois primários e dos agentes oxidantes como permanganato de potássio. Sob a forma de ácido livre, a penicilina é fàcilmente oxidável e perde a ação bacteriostática com grande facilidade. Sob a forma de sal, conserva melhor esta propriedade, dependendo porém de certos fatores, entre os quais a temperatura tem grande importância. $12 \mathrm{Em}$ estado sêco, a estabilidade é muito maior que diluído. Dentre os fatores que inativam a penicilina é necessário referir as enzimas elaboradas por determinadas bactérias; a essas enzimas foi dado o nome de penicilinase. 13 Os sais de penicilina, quando secos, apresentam coloração que varia do amarelo escuro ao castanho claro; na clínica usam-se os sais de sódio e de cálcio. Este é mais fácil de manejar, não é higroscópico, sendo, por êste motivo, lentamente absorvido. Contudo, é mais tóxico que o sal sódico, razão pela qual só é usado para aplicação local. 14 Devido à grande solubilidade dos sais, é fácil diluí-los em água bidestilada ou sôro fisiológico isentos de piretógeno. Sua grande instabilidade exige o uso de vidros rigorosamente neutros, solutos puros e permanência no gêlo.

A penicilina é o mais poderoso agente bacteriano conhecido, com predominante ação bacteriostática, 15 não sendo antisséptica nem exercendo ação bactericida imediata. $16 \mathrm{Na}$ presença de penicilina, mesmo em concentração muito baixa, determinadas espécies bacterianas não sòmente ficam incapacitadas de multiplicar-se mas morrem lentamente. O mecanismo de ação é desconhecido, ainda que as alterações especiais observadas pela primeira vez por Gardner 16 na morfologia bacteriana sugiram que fique inibido, pelo menos, o processo de divisão. Sob o ponto de vista prático, mais importante é o fato de que êste efeito se exerce tanto no sôro, ${ }^{17}$ sangue ou mesmo nos pro-

12. Abraham, loc. cit. 10. Em solução aquosa de $\mathrm{pH}$ entre 6 e 7 a penicilina conserva sua atividade por meses, se mantida a $2^{\circ} \mathrm{C}$. A $37^{\circ} \mathrm{C}$ inativa-se em 24 hs. e a $100^{\circ} \mathrm{C}$, em 30 minutos.

13. Abraham, E. P. e Chain, E. - An enzime from bacteria able to destroy penicillin. Nature 146:837 (dez., 28) 1940. Além do B. coli, são capazes de produzir penicilinase as seguintes bactérias: B. aerogenes, B, typhosum, B. typhimurium, B. flexner, B. pyocyanea, Proteus vulgaris e principalmente o B. paracolon, motivo pelo qual não se usa a via retal para a administração da penicilina.

- Harper, G. P. - Inhibition of penicilin in routine culture media. Lancet 2:567 (novembro, 6) 1943.

14. Florey, M. E. e Florey, H. W. - General and local administration of penicillin. Lancet 1:387 (março, 27) 1943.

15. Abraham, E. P. e outros - Further observations on penicillin. Lancet 2:177 (agôsto, 16) 1941 .

16. Gardner, A. D. - Morphological effects of penicillin on bacteria. Nature 146:837 (dezembro, 28) 1940.

17. Até a data da publicação do trabalho de Bigger, J. W. - Inativation of penicillin by serum. Lancet 2:400 (setembro) 1944, supunha-se que 0 sôro não prejudicava a ação antibacteriana da penicilina. Com êste trabalho ficou provado que o sôro humano ou o sangue inativa em parte a penicilina, parecendo conter um agente penicilino-neutralisante. O grau de inativação varia grandemente com os diferentes espécimes de sôro e é maior nas temperaturas elevadas. 
dutos de hidrólise e de autólise dos tecidos, como no pus 15 o que não se dá com as sulfonamidas devido à ação impediente do ácido-p-aminobenzóico. Dentro de limites muito amplos, a ação da penicilina é independente do número de bactérias presentes. ${ }^{18}$

\section{TOXIDEZ}

Como a penicilina é empregada em forma de sais, o estudo de sua toxidez deve visar tanto a penicilina como o cationte ao qual está ligada.19 Quanto ao cationte adotado, sua toxidez está em ordem crescente: $\mathrm{Na}, \mathrm{Sr}, \mathrm{NH}, \mathrm{Ca}$, $\mathrm{K}, \mathrm{Mg} .20$ Para Gyorgy e Elmes, 21 contudo, o sal cálcico da penicilina, quando purificado, não é mais tóxico para o homem que o sal sódico. Outros estudos sôbre êste assunto 22, 23,24 não firmam conceito exato e o sal sódico continua sendo o mais usado em clínica. O cálcico é empregado para uso tópico ${ }^{14}$ e mesmo em injeções intravenosas $24 \mathrm{com}$ excelentes resultados. Fato de enorme importância é o da diminuição da toxidez acompanhar a purificação do produto. Estudos relativos a êste problema 22 levaram à conclusão que a toxidez inerente à penicilina é mínima, sendo apresentada pelas preparações decorrentes das impurezas não removidas. A penicilina bruta contém uma substância pirogênica que pode ser removida por tratamento adequado. Nas preparações purificadas, 22 a dose de $375.000 \mathrm{U} . \mathrm{F}$. por quilo de pêso e por via venosa não produziu efeitos maléficos. Concentrações muito elevadas de penicilina carecem de efeito sôbre os leucócitos e as hemácias ${ }^{6}$ assim como não têm ação tóxica local sôbre os tecidos, o que vem facilitar sobremaneira o uso local da medicação.

O efeito tóxico da penicilina sôbre as células foi estudado com detalhes por Abrahan e col.15, os quais verificaram seu efeito sôbre os leucócitos, fibroblastos e cultura de tecidos, comparando-o com o de outras substâncias. Estes autores concluíram pela atoxidez da penicilina, pois na concentração de 1:500

18. Hobby, G. L. e outros - Observations on the mechanism of action of penicillin. Proc. Soc. Exper. Biol. a. Med. 50:281, 1942 concluem: 1) o número de bactérias diminúi em proporção geométrica conforme o tempo aumenta em proporção aritmética. 2) $O$ aumento da quantidade de penicilina diminúi o número de germes até um ponto em que a quantidade de bactérias fica estabilizada: êsse ponto é aproximadamente quando $99 \%$ das bactérias tenham sido destruídas. 3) A ação da penicilina é bacteriostática e talvez bacteriolítica, porém só tem ação quando uma multiplicação ativa do germe tem lugar.

19. Hamre, D. M. e outros - The toxicity of penicillin as prepared for chemical use. Am. J. Med. Sc. 206:642, 1943 demonstram que certos animais são mais sensíveis que outros à penicilina.

20. Welch, H. e outros - The relative toxicity of six salts of penicillin. Proc. Soc. Exper. Biol. 55:246, 1944.

21. Gyorgy, P. e Elmes, P. C. - Experiments on toxicity of the calcium salt of penicillin. Proc. Soc. Exper. Biol. a. Med. 55:76, 1944.

22. Florey, H. W. e Jennings, M. A. - Some biological properties of highly purified penicillin. Brit. J. Exp. Path. 23:120, 1942.

23. Hobby, G. L. e outros - Chemotherapeutic activity of penicillin. Proc. Soc. Exper. Biol. a. Med. 50:285, 1942.

24. Herrel, W. E. e Nichols, D. R. - The calc.um salt of penicillin. Proc. Staff. Meet., Mayo Clin. 18:313, 1943. 
não perturba a atividade dos leucócitos in vitro, ao passo que age sôbre os estafilococos e estreptococos na concentração de $1: 1.000 .000$. O sistema nervoso central foi o lugar escolhido para a experimentação sôbre os efeitos de sua aplicação local. Injetaram penicilina intraventricularmente e no córtex de coelhos, verificando que não produzia qualquer lesão macro ou microscópica.

Lyons 25 classificou as reações ao uso da penicilina - que são raras e de pouca gravidade $\rightarrow$ em dois grupos: o primeiro ligado ao preparado e o segundo ao uso indiscriminado de qualquer partida. As do primeiro grupo dependem das impurezas e não da fração ativa penicilínica e são quase sempre evitadas pela filtragem prévia em filtro de Zeitz. São elas: calefrios com ou sem febre, após injeção intravenosa; eosinofilia de 20 a 30\%; ardor no ponto da injeção intramuscular; cefaléia; sabor desagradável após a administração parenteral; vertigem, formigamento na face; zoada nos ouvidos; dôres musculares; tromboflebite da femural. As do segundo grupo, encontradas em certas partidas, devem correr por conta de alguma impureza não removível pelos processos habituais de purificação. Contam-se: urticária; febre nos primeiros dias de tratamento; azotemia transitória; tromboflebite ao nivel das injeções intravenosas repetidas.

A urticária é uma das reações mais freqüentes, ocorrendo, segundo Keefer 26 , em $24 \%$ dos casos e segundo Lyons 25 , em $57 \%$. Aparece a qualquer tempo do tratamento e mesmo poucos dias após sua suspensão. Aparecem placas que condicionam tumescimento dérmico e dôres articulares. O processo dura 3 a 5 dias, sendo beneficiado pelo uso de adrenalina e efedrina. $O$ curso independe da interrupção ou prosseguimento do tratamento e não se repete num mesmo indivíduo em séries diversas do mesmo tratamento. Quando a urticária é intensa, ocorrem também febre e distúrbios gastro-inlestinais. Os sintomas fazem pensar na doença do sôro 27 , porém a eosinofilia não foi encontrada constantemente; os testes de sensibilização cutânea e corneano foram negativos; não foram reveladas precipitinas antipenicilina nem aglutininas heterófilas no sôro. Além disso, os estudos químicos não conferem constituição protéica à penicilina.

Ocorre, raramente, febre sem urticária, nos primeiros três ou cinco dias de tratamento, assim como aumento transitório da azotemia (5 a 10\%) que não se acompanha, porém, de albuminúria, se bem que, algumas vezes, existam cilindros hialinos na urina. O mecanismo dessas reações não está ainda esclarecido.

A tromboflebite foi relacionada a impurezas de certas partidas 26 , emprêgo de concentrações muito elevadas e utilização repetida do mesmo vaso e à predisposição individual. Parece que o emprêgo de concentrações eleva-

25. Lyons, C. - Penicillin therapy of surgical infections in the U. S. Army. J. A. M. A. 123:1007, 1943.

26. Keefer, C. S. e outros - Penicillin in the treatment of infections. A report of 500 cases. J. A. M. A. 122:1217 (agôsto, 28) 1943.

27. Criep, L. H. - Allergy to penicillin. J. A. M. A. 126:429 (outubro, 14) 1944 julga que a alergia não tem relação com a sensibilidade aos esporos de Penicillium e que existem no sòro dêsses pacientes anticorpos reaginas e precipitinas - cujo papel não é ainda conhecido. 
das é a causa primordial, sendo portanto aconselháyel o uso de diluições amplas 28 .

Nenhum efeito tóxico, além dos descritos, foi notado quando se usa a via venosa ou muscular. Nesta, a penicilina diluída em água destilada pode ser dolorosa, o que não acontece se a solução fôr feita em solução salina isotônica 29. A injeção por via subcutânea, que não é usada na prática, produz dor e eritema 15, 19, predispondo à intoxicação pelo acúmulo da droga condicionado pela lenta eliminação.

\section{ABSORÇAO, DIFUSAO E ELIMINAÇAO. VIAS DE INTRODUÇAO}

A penicilina é fàcilmente absorvível. Sua administração por via digestiva leva a resultados diferentes, conforme se faça por via oral, retal ou duodenal. $\mathrm{Na}$ administração duodenal, a absorção se faz ràpidamente, com elevada concentração no plasma 15, 29. Quando administrada por via oral ou retal não há aparecimento da medicação no plasma. Esse fato é explicado pela inativação exercida pelos ácidos e por enzimas bacterianas. O suco gástrico, pelo ácido clorídrico que contém, inativa a penicilina 10 , ao passo que a saliva, a bile e o suco pancreático e entérico não a atacam. $O$ uso de bicarbonato, no sentido de inativar a acidez, alcalinizando o suco gástrico, permite a absiorção e prova que a pepsina não inativa a penicilina 29. O mesmo é notado nos casos de acloridria. A via retal também não pode ser usada, devido ao efeito inativante da flora intestinal, principalmente do B. coli, capaz de produzir penicilinase. O uso de ésteres de penicilina por via oral, devido ao baixo poder saponificante dos ácidos diluídos, liberta a penicilina ao nível do meio alcalino duodenal, aumentando a absorção ${ }^{30}$, que é, porém, 10 vezes menor que pela via subcutânea. Estes fatos levam a concluir que a única via digestiva útil é a duodenal, sendo seu emprêgo possível com o uso de sondas ou cápsulas de acetoftalato de celulose 14 , que só se abrem no duodeno. Como já vimos atrás, o uso da via subcutânea retarda a absorpção e não permite concentrações úteis no sangue 29.

A administração por via intravenosa e intramuscular permite uma absorpção pronta, e rápida elevação do teor sangüíneo. A maior concentração no sangue é conseguida imediatamente pelo emprêgo da via venosa $e$ alguns minutos após injeção intramuscular. Infelizmente, essa concentração decai muito ràpidamente e, 30 a 40 minutos após a injeção, o teor sangüíneo já é 60 a $80 \%$ menor que o inicial. Com o uso da via muscular, a concentração útil conserva-se por mais algum tempo. A manutenção da concentração útil do medicamento no sôro é dificultada pela rápida eliminação pela urina. No sangue, a penicilina é quase totalmente dissolvida no plasma e muito pouco nas células, na proporção aproximada de 10:129. Uma pequena parte da penicilina é inativada no sangue e a maior parte eliminada pela urina.

A velocidade da eliminação depende do estado das funções uro-excretoras. O fato de que, em doentes com insuficiência renal, a penicilina permanece no sangue durante muitas horas, conservando seu poder bacteriostático, levou certos investi-

28. Martin, P. - Heparin in intravenous infections including penicillin therapy. Brit. Med. J. 2:308 (setembro, 2) 1944 aconselha o uso de heparina em dissolução na penicilina a ser injetada contìnuamente por via intravenosa na concentração de 1 unidade Toronto por $\mathrm{cm}^{3}$. Experimentalmente, êste método foi capaz de reduzir a incidência de flebite e trombose causadas por injeções intravenosas de ricinoleato de sódio - um poderoso irritante - de $90 \%$ a 20\% segundo Murray, Brit. J. Surg. 27:567, 1940. Quando uma unidade Toronto não é suficiente para impedir a trombose, a dose pode, sem nenhum perigo, ser aumentada para 3 unidades por $\mathrm{cm}^{3}$. 
gadores ao estudo da eliminação renal dêsse medicamento. no intúito de permitir maior permanência da penicilina no sangue, o que facilitaria a terapêutica, evitando a necessidade de injeção contínua ou muito freqüente. Como acontece com os contrastes urográficos - diodrast, hippuran, etc. - que são eliminados ràpidamente, supôs-se que a penicilina fôsse eliminada, na sua maior parte, pelos túbulos renais. Este fato levou à hipotese de que haveria uma diminuição da eliminação pelo bloqueio terapêutico da função excretora tubular. $O$ bloqueio tem base teórica no conhecido fenômeno da competição de agentes químicos. Quando substâncias como o diodrast, hippuran e o vermelho fenol são dados simultâneamente, ocorre uma manifesta redução na média de excreção de qualquer outra substância. Rammelkamp e Bradley 31 mediram os efeitos da injeção simultânea de penicilina e diodrast, notando que no fim de uma hora haviam sido eliminados só $20 \%$ da penicilina administrada. Beyer e col.32 usaram o ácido p-amino-hipúrico devido à sua pequena toxidez: enquanto nos testemunhas, $78 \%$ da penicilina injetada foram eliminados no fim de uma hora, nos casos em que o bloqueio foi instituído, a eliminação foi só de $33 \%$. Se bem que êstes métodos não estejam ainda em uso corrente na clínica, prometem para breve um aproveitamento melhor dessa medicação tão dispendiosa. A rapidíssima eliminação da penicilina levou certos autores a propor sua recuperação na urina dos pacientes 6,3.3.

Se bem seja excretada principalmente pela urina. a penicilina foi encontrada em outros líquiidos orgânicos como a bile e a saliva 15, 34. Não foi, contudo, possível encontrá-la em outros humores, como a lágrima, suco pancreático e líqüido cefalorraquidiano 15,29. Estes fatos vieram evidenciar que a difusão da penicilina não é uniforme; sua passagem da corrente sangüínea para as cavidades serosas é difícil e portanto, no tratamento das infecções das meninges, cavidade pleural, articular e peritôneo, a via local é mais indicada que a sistêmica. A base fisiológica da impermeabilidade relativa aparente destas membranas, mantém-se, ainda, sem elucidação. Nos processos supurativos do sistema nervoso central torna-se obrigatório o uso da via intratecal.35

Quando injetada nos espaços aracnóideos, a penicilina é lentemente absorvida e lentamente excretada nos indivíduos normais, 36 a ponto de poder ser encontrada no líqüido cefalorraquidiano 31,5 hs. após a injeção de 10.000 U.Ox. Em pacien-

29. Rammelkamp, C. H. e Keefer, C. S. - The absorption, excretion and distribuition of penicillin. J. Clin. Invest. 22:425, 1943.

30. Meyer, K. e outros - On esters of penicillin. Science 97:205, 1943.

- Meyer, K. e outros - The chemotherapeutic effect of esters of penicillin. Proc. Soc. Exper. Biol. a. Med. 53:100, 1943.

31. Rammelkamp, C. H. e Bradley, S. E. - Excretion of penicillin in man. Proc. Soc. Exper. Biol. a. Med. 53:30, 1943.

32. Beyer, K. H. e outros - The prolongation of penicillin retention in the body by means of p-amino-hippuric acid. Science 100:107 (agôsto, 4) 1944.

33. Editorial. Lancet 2:542 (outubro, 21) 1944.

34. Rammelkamp, C. H. e Helm Jor., J. D. - Excretion of penicillin in bile. Proc. Soc. Exper. Biol. a. Med. 54:31, 1943.

35. Herrel, W. E. - The clinical use of penicillin. An antibacterial agent of biologic origin. J. A. M. A. 124:622 (março) 1944.

36. Rammelkamp, C. H. e Keefer, C. S. - The absorption, excretion and toxicity of penicilin administered by intrathecal injection. Am. J. Med. Sc. 205:342 (março) 1943. 
tes com menıngite, a absorção é mais rápida 29,37 , assim como, pela rotura da barreira hemoliquórica, há possibilidade da penicilina injetada intramuscular ou intravenosamente penetrar no líqüido cefalorraquidiano. Rosenberg e col.38 injetaram 20.000 a 40.000 U.Ox. por via intravenosa e intramuscular em 8 pacientes com meningite, verificando, 60 a 140 minutos depois, a presença de penicilina no líqüido cefalorraquidiano em concentração útil ; concluíram pela desnecessidade dá injeção intratecal nos casos de meningite. Julgamos precipitada essa opinião, devido ao pequeno número de casos observados e pelo fato da barreira hemoliquórica ser diferentemente rompida em cada caso de meningite. A injeção intratecal de penicilina poderia ser dispensada, se, em dado caso clínico, a dosagem da penicilina no líquor revelasse teor elevado capaz de ação bacteriostática eficiente. Sem êste cuidado seria arriscado o uso exclusivo da via sistêmica. ${ }^{39}$

Injetada por via lombar, a penicilina difunde-se por todo o sistema cavitário do sistema nervoso, tendo sido encontrada no líquor colhido na cisterna magna $e$ no terceiro ventrículo. 29 Spurling 25 prefere a via ventricular. julgando-a mais apta a assegurar a chegada do medicamento aos segmentos inferiores. Esta via é também preferida por Cairns e col.40, os quais não encontraram penicilina nos ventrículos laterais após injeção lombar em 2 dos 8 casos de meningite por êles tratados. A via suboccipital é perigosa nos doentes agitados, mas pode ser imprescindível quando existir bloqueio do canal raquidiano. Nos casos graves, principalmente nas meningites a pneumococo e a estaficoco, germes altamente purulentos e que produzem aracnoidite adesiva, o uso das diversas vias - lombar, cisternal e ventricular - facilita a difusão do medicamento a todo o sistema cavitário interno e externo do sistema nervoso central, pondo em maior contacto o medicamento com toda a área inflamada.

Felizmente, o uso da via intratecal pode ser feito sem receio de reações tóxicas, desde que a dose usada não ultrapasse 10.000 a 15.000 U. Ox. Estas doses raramente produzem cefaléia, vômitos, aumento de pressão liquórica e pleocitose no líquor. Algumas reações mais graves, como choque, foram descritas devido ao uso intratecal de grandes concentrações do medicamento.40

Em conclusão, a penicilina só deve ser empregada por via venosa, muscular, duodenal ou tópica, sendo proscritas as vias oral, retal e subcutânea. Em presença de infecções septicêmicas ou acompanhadas de bacteremia, deve-se empregar a via

37. Editorial - Simplified therapy of meningitis. J. A. M. A. 126:370 (outubro, 7) 1944.

38. Rosenberg, D. H. e Sylvester, J. C. - Excretion of penicillin in the spinal fluid in meningitis. Science 100:132 (agôsto, 11) 1944.

39. Pilcher, C. e Meachan, W. F. - The chemotherapy of intracranial infection. III: The treatment of experimental staphylococcic meningitis with intrathecal administration of penicillin. J. A. M. A. 123:330 (outubro, 9) 1943. Neste trabalho experimental, os AA. não obtiveram resultado pelo uso da via venosa mas sim pelo da via cisternal.

40. Cairns, H. e outros - Pneumococcal meningitis treated with penicillin: Lancet 1:655 (maio, 20) 1944, sugerem que o melhor método de se conseguir uma boa concentração de penicilina no líqüido cefalorraquidiano é fazer simultâneamente injeção lombar e ventricular. Rotineiramente, a via lombar pode ser a única usada, mas a via ventricular deverá ser empregada se não houve pronta melhora ou se se suspeitar de bloqueio. Nos primeiros dias de uma meningite, os ventrículos parecem ser menores que normalmente, mas em seguida tornam-se dilatados, estabelecendo franca comunicação com o espaço subaracnóideo. 
venosa de preferência e. eventualmente, a intramuscular. Nas afeç̧ões localizadas, deve-se usar a via muscular porque a mais lenta eliminação permite a manutenção do efeito útil da medicação por mais tempo além de que o emprêgo freqüente da via venosa traz o perigo da endoflebite. Nos casos de meningite ou encefalite, o uso da via intratecal, por inję̧̃es lombar, suboccipital e ventricular, é obrigatória. A via ventricular deve ser reservada para os casos em que a resposta à medicação não seja satisfatória ou quando uma inflamação muito purulcnta interceptar o livre trânsito do líquor pelos canais do sistema nervoso central.

\section{ACAO ESPECFFICA}

A penicilina é o antibacteriano mais seletivo que se conhece, a ponto de ser utilizado em meios de cultura, no intuito de evitar o crescimento de certas bactérias e permitir o de outras 5, 41. Por êsse método, sua ação foi estudada sôbre os diversos agentes patogênicos, que poderão ser assim divididos:

1) Germes SENSfveis À PENICILINA

a) bactérias Gram-positivas: Staphylococcus aureus, Staph. albus (algumas linhagens). Sireptococcus viridans, St. pyogenes, St. salivarius, Diplococcus pneumonix, Corynebacterium diphtherix, Clostridium tetani, Cl. perfringens (B. welchii), Cl. novyi (B. oedematiens), Cl. septicum (vibrião séptico), $\mathrm{Cl}$. botulinum, Bacillus anthracis, B. subtilis, Actinomyces bovis.

b) bacterias Gram-negativas: Neisseria gonorrheæ, N. intracellularis, Micrococci, Vibrio coma.

c) Treponemas, espirilos $e$ virus: Treponema pallidum, Tr. recurrentis (Borrelia novyi), Leptospira ictero-hemorrhagize, Spirillum minus, Virus da psitacose e da ornitose.

2) Germe? Relattivamentt SeNsiveis: Salmonella typhi e S. gaertner.

3) Germes Não SENSfVEIS À PENICILINA:

a) bactérias Gram-positizas: Staphylococcus albus (algumas linhagens), Streptococcus fecalis, Mycobacterium tuberculosis, Brucella melitensis, Br. abortus.

b) bactérias Gram-negativas: Pseudomona aeruginosa (B. piociânico), Klebsiella pneumoniæ (B. de Friedländer), Hemophilus influenzæ (B. de Pfeiffer), Escherichia coli, Proteus vulgaris, Shigella disenteriæ, Salmonella paratyphi A e B, S. enteritides, Pasteurella pestis, Erythrobacillus prodigiosus, Vibrio choleræ.

c) Agentes patogênicos de outros tipos: Monilia albicans, M. candida, M. krusei, Blastomicetos, Toxoplasma, Plasmodium vivax, Filária e o Virus da mononucleose infecciosa.

Os germes da família coccaceae (estreptococo, estafilococo, pneumococo, meningococo e gonococo) são os que mais sofrem. a ação da penicilina. Entre todos, o Streptococcus hemolyticus é mais sensível. O Streptococcus viridans e o não hemolítico termófilo (Streptococcus fecalis) são resistentes. O gênero Staphylococcus como um todo, é 2 a 4 vezes mais resistente que o Streptococcus hemolyticus, porém, a sensibilidade de cada amostra é susceptível de grandes variaçóes. A concentração útil para o estreptococo é de $0,010 \mathrm{U} . \mathrm{Ox}$. por $\mathrm{cm} 3$, ao passo que para o Staphylococcus aureus é necessária a concentração de 0,156 U.Ox. por cm3.

41. Fleming, A. - On the antibacterial action of cultures of a penicillin with special reference to their use in the isolation of $b$. influenzae. Brit. J. Exper. Path. 10:226 (junho) 1929.

$\rightarrow$ Fleming, A. e Maclean, I. H. - On the occurrence of influenza baccili in the mouts of normal people. Brit. J. Exper. Path. 11:127 (abri1) 1930.

- Cleming, A. - On the specific antibacterial properties of penicillin and potassium tellurite. J. Path. a. Bact. 35:831 (novembro) 1932.

- Maclean, I. H. - A modification of the cough plate method of diagnosis in whooping cough. J. Path. a. Bact. 45:472 (setembro) 1937. 
Não só os cocos, mas também as bactérias da família Bacillaceae, no seu gênero Clostridium são sensíveis, sendo que as espécies proteolíticas o são $\mathbf{5}$ vezes menos que o Staphylococcus aureus; contudo, o Cl. tetani e o $\mathrm{Cl}$. tetanomorphum o são tanto quanto o Streptococcus hemolyticus. Os esporos são tão sensíveis como as formas vegetativas. Tanto experimental como clinicamente, o $\mathrm{Cl}$. welchii sofre a ação da penicilina, 42 a qual tem, também, ação preventiva.

Formas mais evoluidas, como Borrelia e Treponema são vulneráveis. A sífilis primária parece esterilizável pela penicilina 43 e mesmo a sifilis nervosa seria beneficiada de uma maneira igual ou mesmo superior que pela terapêutica malariarsenical. 43

\section{DOSAGEM}

No início das experiências clínicas, o estabelecimento das doses e da freqüência da administração constituia problema de grande complexidade. As primeiras experiências indicavam que os diversos organismos patogênicos tinham sensibilidade diferente à ação da penicilina; estudos mais detalhados vieram mostrar que mesmo linhagens diversas de um mesmo germe apresentam largas variações em sua susceptibilidade. Cepas de estreptococos hemolíticos (grupo A da classificação de Lancefield), gonococos e meningococos mostraram-se muito sensíveis, seguidas pelos pneumococos, Staphylococcus aureus, Streptococcus viridans e Staphylococcus albus. Algumas linhagens mostraram-se altamente resistentes. 45 Outro fato que aumentava a complexidade do problema era a existência de linhagens resistentes à penicilina. Cepas não resistentes podem ser induzidas a tal, fazendo-as crescer em meio cuja concentração em penicilina vá sendo aumentada lentamente, durante longo tempo. Este fato pode ocorrer in vitro e in vivo, como já foi demonstrado para o Staphylococcus aureus 15, 26, 45, Diplococcus pneumoniae 47 e o Streptococcus hemolyticus. 48 Felizmente, essas linhagens penicilino-resistentes não o

42. Hac, L. R. e Hubert, A. C. - Penicillin in treatment of experimental Clostridium welchii infection. Proc. Soc. Exper. Biol. a. Med. 53:61, 1943. $124: 360,1944$.

Mc Knight, W. B. e outros - Penicillin in gas gangrene. J. A. M. A.

- Mc Intosh, J. e Selbie, F. R. - Zinc peroxide proflavine and penicillin in experimental Clostridium welchii infections. Lancet 2:750, 1942.

43. Mahoney, J. F. e outros - Penicillin treatment of early syphilis. J. A. M. A. 126:63 (setembro, 9) 1944.

- Moore, J. E. e outros - The treatment of early syphilis with penicillin. J. A. M. A. 126:67 (setembro, 9)- 1944 .

44. Stokes, J. H. e outros - The action of penicillin in late syphilis. J. A. M. A. 126:73 (setembro, 9) 1944.

45. Rammelkamp, C. H. e Maxon, T. - Resistance of Staphylococcus aureus to the action of penicillin. Proc. Soc. Exper. Biol. a. Med. 51:386 (dezembro) 1942.

46. Fleming, A. - Streptococcal meningitis treated with penicillin (measurement of bacteriostatic power of blood and c.r.f.). Lancet 2:434 (outubro, 9) 1943.

47. Schmidt, L. H. e Sesler, C. L. - Development of resistance to penicillin by pneumococci. Proc. Soc. Exper. Biol. a. Med. 52:353 (abril) 1943.

48. McKee, C. M. e Houck, C. L. - Induced resistance to penicillin of cultures of Staphylococci, Pneumococci and Streptococci. Proc. Soc. Exper. Biol. a. Med. 53:33 (maio) 1943. 
são às sulfonamidas, 49 assim como sua virulência decresce na proporção que sua resistência aumenta,50 o que contrasta com a retenção de virulência dos germes sulfonamido-resistentes. $\mathrm{O}$ progredir das pesquisas tornou viável, na prática do laboratório clínico, 46 fazer 0 teste de sensibilidade à penicilina da linhagem em ação no caso mórbido. Este processo é recomendado quando não há uma resposta satisfatória às doses habituais do medicamento e tem importância na determinação dis doses a serem empregadas.

A concentração útil varia, pois, para cada tipo de germe e para um mesmo tipo, com cada linhagem. Ainda não se estabeleceu, como já se fêz com as sulfonamidas, uma fórmula rígida de doses a serem usadas. Assim é que as doses variam para cada autor e para cada tipo de inflamação. $O$ fato de que é necessário manter uma concentração útil constante no ponto de infecção. 51 muitas vezes difícil de conseguir e ainda mais difícil- de dosar, torna mais complexo o problema. A manutenção da dose útil é difícil devido à rapidíssima eliminação da penicilina e à dificuldade em sua difusão. 52 Para sanar esta última dificuldade emprega-se, se a medicação fôr usada por poucos dias ( 2 a 3 ), injeções repetidas cada 3 horas, intramuscularmente, de 15.000 a 25.00053 U.Ox. ${ }^{54}$, diluídas em 2 c.c. de água destilada ou sôro fisiológico. Se a medicação fôr usada por muitos dias, deve-se

49. Spink, W. W. e outros - Comparative in vitro resistance of Staphylocococci to penicillin an to sodium sulfathiazole. Proc. Soc. Exper. Biol. a. Med. 55:207, 1944.

- Powel, H. M. e Hemieson, W. A. - Response of sulfonamide (sulfapyridine) fast Pneumoçocci to penicillin. Proc. Soc. Exper. Biol. a Med. 49:387, 1942.

50. McKee, C. M. e Houck, C. L. - Induced Penicillin resistance in a Pneumococcus type III culture. Federation Proceedings 2:100 (março, 16) 1943.

51. Bigger, J. W. - Treatment of staphylococcal infections with penicillin by intermittent sterilisation. Lancet $2: 497$ (outubro, 14) 1944, acredita que a falência na esterilização de caldo contendo Staphylococcus pyogenes é devido a um pequeno número de estafilococos chamados persistentes. A insensibilidade dêsses germes à penicilina é devida, provàvelmente, a não estarem em fase de divisão, pois é sabido que a penicilina só ataca os germes que se estão dividindo. Como os descendentes dêsses germes persistentes são mortos pela penicilina, Bigger sugere uma medicação alternada de penicilina e sulfonamida. Far-se-ia uma grande dose inicial de $400.000 \mathrm{U}$. Ox no primeiro dia. No dia seguinte, usar-se-ia sufonamida, no terceiro dia 100.000 U. Ox de penicilina e assim por diante.

52. Para contornar a impermeabilidade da barreira hemoliquórica empregam-se injeções intratecais de penicilina, e para diminuir a velocidade da eliminação, foi proposto o bloqueio dos túbulos renais. Contudo, êste procedimento ainda não entrou na prática clínica e a concentração deve ser mantida por meio de injeções repetidas cada $3 \mathrm{hs}$. ou injeções contínuas intravenosas ou intramusculares. Este último meio é o melhor, pois não produz flebite, permitindo, ainda, um menor gasto de medicamento. Mc Adam, I. W. H., e outros - Systemic administration of penicillin, Lancet 2:336 (setembro, 9) 1944, descreveram um aparêlho destinado a êste método.

53. Dose recomendada pelo Ministério de Saúde da Inglaterra. Penicillin progress. Editorial. Lancet 2:348 (setembro, 9) 1944.

54. A atividade da penicilina é medida em unidades Oxford (U. Ox), que é a quantidade de penicilina contida no volume de 1 c.c. que, posta sôbre 
fazer injeção contínua na veia, ou melhor, no músculo, porque o método anterior não garante a manutenção de completa bacteriostase no sôro e desperdiça muito medicamento.

Nas moléstias do sistema nervoso é obrigatório o uso da via intratecal. A dose ć de $10.000 \mathrm{U} .0 x$., diluída em $10 \mathrm{c.c}$. de solução isotônica de $\mathrm{ClNa}$, introduzida lentamente cada 12 horas. Esta dose tem sido largamente empregada, sem que motivasse reações; doses maiores, de 15.000 ou 20.000 U.Ox., foram também usadas, mas sobrevieram reações, algumas das quais graves. Como já foi assinalado acima, as injeções podem ser feitas tanto por via lombar como occipital $e$. eventualmente, ventricular.55 Se, além da meningite, houver foco em outro ponto do organismo ou se houver septicemia, é necessário fazer a medicação sistêmica por via intravenosa ou intramuscular. A introdução contínua de $5.000 \mathrm{U}$.Ox. por hora ou 20.000 U. Ox. cada 3 horas, por via intramuscular, são os métodos mais usados. Se o tratamento necessita ser continuado por mais de 3 dias, a via muscular é a de escolha.56 O melhor método é o de injeção contínua intramuscular.14

Concluindo, a dosagem varia com o local da infecção o tipo do germe e a gravidade da moléstia. Se a infecção fôr generalizada, impõe-se a medicação sistêmica com doses mais elevadas que aquelas usadas em injeções intratecais. Os germes variam grandemente em relação à sua susceptibilidade à penicilina, havendo alguns penicilino-resistentes e outros persistentes; aqueles exigem o tratamento sulfonamídico, êstes o tratamento penicilínico intermitente.

\section{RESULTADOS}

Meningites a meningococos - Diversos autores relataram casos de meningite cerebrospinhal epidêmica tratados com penicilina.57 Esses trabalhos constam, porém, de pequeno número de casos ou mesmo de casos isolados. O único tra-

uma cultura em placa de uma dada amostra de estafilococo, produz um halo de $24 \mathrm{~mm}$. de diâmetro. Outros a definem como a quantidade mínima de penicilina que, dissolvida em 50 c.c. de caldo simples, inibe o crescimento do Staphylococcus aureus. Quando $1 \mathrm{mgr}$. de penicilina contém uma U. Ox. e impede o crescimento do germe a 1:50.000 chama-se Unidade Florey. Os pesquisadores tendem, hoje, a considerar estas duas unidades como sinônimas?. Picalluga, F. - Penicilina. Rev. Med. Lat. Americana 28:590-608, 1943, chama de unidade clínica diária a dose média necessária para manter uma concentração adequada no organismo, ou sejam $100.000 \mathrm{U}$. Ox.

55. Mc Cune, W. S. e Evans, J. M. - Intraventricular penicillin in the treatment of staphylococcic meningitis, J. A. M. A. 125:705 (julho, 8) 1944 acreditam ser lícito concluir que a circulação normal do líquor pode impedir a passagem de drogas do sistema raquidiano para o ventricular, especialmente nas meningites, nas quais é possível a obstrução por exsudatos e aderências aracnóideas.

56. Morgan, H. V., Christie, R. V. e Roxburgh, I. A. Brit. Med. J. $1: 515,1944$.

57. Keefer, C. S. e outros - Penicillin in the treatment of infections. J. A. M. A. 122:1217 (agôsto, 28) 1943.

- Lyons, C. - Penicillin therapy of surgical infection in the United States Army. J. A. M. A. 123:1007 (dezembro, 18) 1943.

- Martin, H. D. e Hobby, G. L. - The clinical use of penicillin: observations on 100 cases. J. A. M. A. 124:611 (março, 4) 1944.

- Peixoto, I. - Meningite cerebro-espinhal e penicilina. Brasil Méd. 58:445 (novembro, 18) 1944. 
baiho com número regular de casos é o de Rosenberg e Arling 58 que trataram 31 c, depois, 65 casos, com uma única morte em cada grupo, o que dá uma percent:gem de $98 \%$ de cura. Os dois falecimentos ocorreram em pacientes cujo estado era gravíssimo ao entrar no hospital. Quando deram entrada no hospital, 32,3\% dos pacientes estavam em coma e 36\% em semicoma. Em $72 \%$ dos casos havia septicemia, com petéquias, púrpuras, síndrome de Waterhouse-Friderichsen, artrite, poliartrite, epididimite e orquite. Em $94 \%$ dos casos, o líqüido cefalorraquidiano mostrou-se turvo, com pleocitose de 21 a 50.100 células por $\mathrm{mm} 3$, dando uma média de 11.700 células, cuja maioria $(88 \%)$ era constituída de polimorfonucleares. Em $74 \%$ dos casos, o germe foi evidenciado no líquor e em $15 \%$ no sangue. O tratamento foi instituído com 10.000 U.Ox. de sal sódico de penicilina dissolvido em 10 c.c. de solução isotônica de $\mathrm{ClNa}$ e injetada lentamente na raque; 5.000 U.Ox. por hora, na veia, de maneira contínua (40 U.Ox., em cada c.c. da solu. ção de dextrose a 5\%); além disso, foi usada medicação geral: 3.000 c.c. de líqüidos por dia, transfusões de sangue e plasma, injeções de epinefrina e acetato de desoxicorticosterona. A cura processou-se ràpidamente; após 24 horas, os pacientes tornaram-se conscientes e a febre desapareceu em 72 horas, em quase todos os pacientes. Em 24,6\%, ela permaneceu de maneira intermitentc, mas o líqüido cefalorraquidiano normalizou-se logo, com pronta redução do número de células e do teor proteico e aumento da taxa de glicose. O exame bacterioscópico mostrou que o líquor tornava-se asséptico até a $4 .^{\mathrm{a}}$ injeção de penicilina.

Meningites a estreptococos - Quando o agente é o Streptococcus hemolyticus (grupo A da classificação de Lancefield) não há, atualmente, indicação para o emprêgo da penicilina, devido à escassez dêste medicamento e a resposta satisfatória dêsse germe à sulfonamidoterapia. Infeções meníngeas devidas a outros Streptococcus hemolyticus que não do tipo $\mathrm{A}$ e ao Streptococcus viridans são raras. In vitro, as linhagens de Streptococcus hemolyticus dos grupos B, C, D, E, F, G, têm-se mostrado sensíveis, a não ser algumas cepas do grupo $D$ que são resistentes. As linhagens de estreptococos não hemolíticos são quatro vezes mais resistentes que aquelas do grupo A. Os poucos casos relatados de meningite por estreptococo não hemolítico foram mortais. $26 \mathrm{Um}$ caso de meningite a estreptococo anaeróbio após fratura do crânio, relatado por Keefer, 26 teve boa evolução.

Meningites a estafilococos - Experimentalmente, Pilcher e Meachan 39 verificaram que o tratamento por via venosa não tinha efeito algum, ao passo que a inoculação intracisternal de penicilina reduziu muito o número de mortes. $O$ tratamento dêste tipo de meningite é dificultado pela grande tendência que apresenta de bloquear o canal raquidiano. A medicação deverá ser feita o mais precocemente possível para evitar essas bridas, e as doses devem ser muito elevadas, porque o estafilococo resiste mais que os estreptococos à ação da penicilina. Caso os septos meníngeos venham a se formar, dever-se-á injetar a penicilina acima e abaixo do ponto bloqueado, tentando romper a aderência. Em último caso estará indicada a laminectomia. Quando se forma abscesso, indica-se formalmente seu esvaziamento. Evans 59 relatou dois casos de meningite a estafilococos. Num dêles havia meningite e abscesso cerebral e no outro a infecção ocorreu em seguida

58. Rosenberg, D. H. e Arling, P. A. - Treatment of cerebrospinal fever with penicillin. U. S. Navy Bull. 43:281 (agôsto) 1944.

- Rosenberg, D. H. e Arling, P. A. - Penicillin in treatment of meningitis. J. A. M. A. 125:1011 (agôsto, 12) 1944.

59. Evans, A. L. - The treatment of intracraneal infections with penicillin. J. A. M. A. 124:641 (março, 4) 1944. 
a laminectomia para retirada de um hemangioma que blorgueava o canal raquidiano. Os dois casos decorreram hem, tendo sido feito tratamento local e sistemico. Devido ao pequeno número de casos relatados, é difícil, no momento atual, ter-se uma impressão sôbre o quanto melhorou o prognóstico das meningites a estafilococos. O que não há dúvida é que êle é bem pior que o das meningites meningocócicas e estreptocócicas, porém parece ser melhor que quando tratado pelas sulfonamidas.

Meningites a pneumococos - A meningite pneumocócica, devido à grande morbidade e alta mortalidade, não obedecendo a tratamento algum, tem sido aquela de pinr rrognóstico. Antes da quimioterapia. a mortalidade era muito alta 90\%.60 Com $n$ advento das sulfonmidas. essa percentagem baixou, variando, segundo os autores, de $31 \%$ a $80 \% .61$ A disparidade observada, quanto aos resultados obtidos. talvez seja explicada pelo número pequeno de doentes tratados, pela ação diferente dos diversos componentes do grupo das sulfonamidas e a importância que tem a idade dos pacientes no relativo ao prognóstico das meningites pneumocócicas. Assim é que a sulfanilamida tem pouca ação, permanecendo alta a mortalidade $(94 \%)$; a sulfapiridina, o sulfatiazol e a sulfadiazina têm maior eficácia, reduzindo esta percentagem para 60 a $70 \%$. Com o uso combinado dêstes últimos preparados e sôro antipneumocócico, foi possível reduzir a mortalidade $\mathrm{cm}$ crianças com menos de dois anos de idade a $78 \%$ e em indivíduos com mais de dois anos a $36 \% .62$

Com a descoberta da penicilina, observou-se que o pneumococo é sensível, in vitro. ว̀. sua ação. ${ }^{15}$ Estudos experimentais 63 demonstraram que a meningite pneumocócica pode ser controlada pela penicilina e que $84 \%$ dos casos tratados por injeção intratecal evoluíram satisfatòriamente. Estas experiências animaram n emprégo da penicilina em casos humanos. Os primeiros doentes tratados 40 foram bem sucedidos, porém o estudo de maior número de casos veio mostrar que a penicilina freia o curso da moléstia. mas não é capaz de parar completamente a. infecção, apesar do tratamento ser enérgico: local e geral. A mortalidade manteve-se em $67 \%$. Ültimamente, foram relatados ótimos resultados $64 \mathrm{com}$ o emprêgo combinado de penicilina, sulfadiazina ou sulfapiridina e sôro específico, pois a mortalidade cain para $8.5 \%$, sendo $10 \%$ em crianças com menos de dois anos e $0 \%$ em pessoas com mais idade. Esta percentagem foi obtida, tendo em vista 12 casos - número ainda insuficiente - tratados recentemente no Sydenham Hospital e Harriet Lane Home, Baltimore. O tratamento empregado foi o seguinte:

60. Goldste'n, H. Z. e Goldstein, H. I, - Review of literature on Pneumococcus meningitis. Intern. Clin. 3:155 (setembro) 1927.

61. Steele, C. W. e Gottlieb, J. - Treatment of pneumococcal meningitis with sulfanilamide and sulfapyridine. A statistical study of all reported cases in which chemotherapy was used, with or without specific antipneumococcus serum. Arch. Int. Med. 68:211 (agôsto) 1941.

62. Hodes, H. L. e outros - Sixty cases of Pneumococci meningitis treated with sulfonamides. J. A. M. A. 121:1334 (abril, 24) 1943.

63. Pilcher, C. e Meachan, W. F. - The chemotherapy of intracraneal infections. IV: The treatment of pneumococcal meningitis by intrathecal administration of penicillin. J. Neurosurgery 1:76 (janeiro) 1944.

64. Warring, A. J. e Smith, M. H. D. - Combined penicillin and sulfonamide therapy in the treatment of pneumococcic meningitis. J. A. M. A. 126:418 (outubro, 14) 1944. 
a) Sulfonamida (sulfadiazina ou sulfapiridina) - Dose inicial de $0,05 \mathrm{gr}$. de sal sódico por quilo de pêso em crianças, que, dissolvida em água destilada na concentração de $5 \%$, foi injetada na veia. Ao mesmo tempo, os pacientes recebiam 0,1 gr. por quilo de peso por via oral ou gástrica. Em seguida 0,2 gr. por quilo de pêso eram dados por dia, cada 4 hs. Os adultos recebiam inicialmente $3 \mathrm{gr}$. intravenosamente e 2 a $4 \mathrm{gr}$. por via oral. Subseqüentemente, recebiam $1 \mathrm{gr}$. cada 4 hs. O teor sangüíneo era determinado diàriamente e as doses manipuladas no intuito de manter a concentração de 6 a 12 mgr. por 100 c.c. no sangue; b) Penicilina - As crianças pequenas recebiam 5.000 a 10.000 U.Ox. intratecalmente por dia. Nos 2 ou 3 primeiros dias, essa dose era dividida e injetada duas vezes. Nos dias subseqüentes, a dose era reduzida à metade e injetada tôda de uma vez. Recebiam ainda 1.500 a 2.500 U.Ox. por via intramuscular cada 3 hs. dia e noite, perfazendo um total de 12.000 a 20.000 U.Ox. por dia. Crianças crescidas e adultos recebiam 10.000 a 20.000 U.Ox. por via intratecal e 5.000 a 10.000 U.Ox. intramuscularmente cada 3 hs. dia e noite; c) sôro de coelho, específico para cada tipo de pneumoco, foi introduzido segundo o método de Hodes, Smith e Ickes 62 ; d) processos cirúrgicos - Drenagens dos focos de infecção deverão ser realizadas o mais precocemente possível; e) medicações gerais, como administração de fluido por via oral ou parenteral caso haja vômitos, transfusões de plasma sangüíneo, injeção de glicose a $5 \%$ ou solução isotônica de cloreto de sódio caso haja febre alta ou colapso. Sedativos também deverão ser empregados.

Também Dawson e Hobby, 65 tratando 4 casos, e Barker 66 puderam, com esta associação, curar todos seus pacientes.

Abscessos encefálicos - Os abscessos continuam, mesmo com o emprêgo da penicilina, a ter prognóstico muito grave. A drenagem cirúrgica se impóe quando praticável. A penicilina será colocada localmente. Se não fôr localizado o processo, será feita medicação sistêmica e injeção intratecal. Dos 5 casos relatados por Keefer,26 três por estafilococos com bacteremia e dois por estreptococo não hemolítico, só um sobreviveu. Um caso curado com penicilina e intervenção cirúrgica foi relatado por Evans. ${ }^{99} \mathrm{Mc}$ Adam e col.52, relataram 2 casos de abscessos epidurais curados por injeção contínua de penicilina na cavidade do abscesso, tendo conseguido um teor bacteriostático satisfatório no sôro.

Trombose do seio cavernoso - As tromboses ou tromboflebites do seio cavernoso infectado pelo estafilococo eram sempre mortais até o aparecimento das sulfonamidas. Com esta medicação, alguns casos de cura foram relatados. Grove 67 descreveu detalhadamente a anatomia e o significado clínico do seio cavernoso e seus tributários; segundo êle, quando se desenvolve uma tromboflebite da veia facial, como resultado da incisão de um furúnculo do lábio superior ou à extração de um fio do supercílio ou da narina, cujo folículo esteja infectado, a mor-

65. Dawson, M. H. e Hobby, G. L. - The clinical use of penicillin, observation in one hundred cases. J. A. M. A. 124:611, 1944.

66. Barker, L. T. - Gradenigo syndrome complicated by pneumococcic meningitis: recovery after intensive treatment with penicillin and sulfadiazine. Am. J. Med. Sc. 206:701, 1943 obteve bons resultados com penicilina por via venosa e raqueana associada a sulfadiazina em um doente com otite média, cefaléia, paralisia do VI par do mesmo lado complicada com meningite pneumococica.

67. Grove, W. E. - Septic and aseptic types of thrombosis of the cavernous sinus. Arch. Otolaryng. 24:29 (julho) 1936. 
talidade é de $100 \%$ se a inflamação se estende através das veias angular e oftálmica ao seio cavernoso (via anterior). Mortalidade menor, de $99 \%$, é originada pela trombose dos seios lateral ou pterigóideo. Mac Neal e Cavallo 68 relataram, numa revisão feita em 1937, sòmente 7 casos curados de trombose do seio cavernoso, com bacteremia por estreptococos. Outros casos isolados, curados com uso de sulfatiazol, foram relatados. ${ }^{69}$ A moléstia continuou sendo muito grave, mesmo com a adição de heparina ao tratamento sulfonamídico com fito de diminuir a coagulação do sangue. O emprêgo da penicilina foi relatado em alguns casos. Hageman e col.70 curaram um paciente com mastoidite, petrosite, meningite, bacteremia e trombose do seio cavernoso devida a um pneumococo do tipo III, utilizando ligadura da veia jugular, mastoidectomia e tratamento penicilínico intravenoso, intratecal e tópico na ferida operatória. Goodhill 71 curou um caso de tromboflebite do seio cavernoso no qual a terapêutica sulfatiazólica mais heparina havia falhado. Também Nicholson e Anderson 72 empregaram a penicilina com sucesso num caso grave cujo ponto de partida foi um furúnculo na narina. $\mathrm{O}$ tratamento perdurou por 30 dias, permanecendo, como seqüela, uma atrofia óptica unilateral. São ainda poucos os casos, não permitindo nenhuma conclusão. Dada a gravidade da moléstia, é aconselhável o tratamento precoce pela administração intensiva de penicilina combinada com sulfonamida e heparina.

Osteomielite dos ossos do crânio e da raque - $\mathrm{O}$ tratamento penicilínico tem dado bons resultados nestes casos. E necessário o emprêgo local e, às vezes, o sistêmico. Tem interêsse $o$ aspecto radiológico dos ossos infectados, 6 durante o tratamento. As radiografias, durante a primeira semana, sıgerem uma piora, porque se processa uma rarefação muito rápida no osso afetado ou em tôrno dos seqüestros já formados. Radiografias posteriores demonstram a rápida neoformação do tecido ósseo. Quando se trata de casos agudos, a penicilina impede a formação de seqüestros e, nos casos crônicos, impõe-se a retirada dos seqüestros cxistentes.

Neurossifilis - $\mathrm{O}$ tratamento penicilínico tem efeito benéfico sôbre a neurossífilis, quer se considere o quadro clínico, quer o liquórico. $\mathrm{Na}$ sífilis ocular, os processos inflamatórios simples respondem bem e as complicações como neurite e queratite intersticial melhoram, se bem apresentem resistência à medicação e

68. Mac Neal, W. J. e Cavallo, M. E. - Streptococcus bacteremia and afferent thrombosis of the cavernous sinus recovery. J. A. M. A. 109:2139 (dezembro, 25) 1937.

69. Wolfe, C. T. e Wolfe, W. C. - Thrombosis of the cavernous sinus with recovery. Arch. Otolaryng. 33:81 (janeiro) 1941.

$\rightarrow$ Skemp, H. I. e outros - Thrombosis of the cavernous sinus with staphylococcic septicemia treated by intravenous injection of sodium sulfathiazol with recovery. Arch. Otolaryng. 34:1025 (novembro) 1941.

- Barnshaw e outros, citados por Schall, L. R. - Treatment of septic thromboflebitis of the cavernous sinus. J. A. M. A. 117:581 (agôsto, 23) 1941.

70. Hageman, P. O. e outros - Penicillin: clinical study of its therapeutic effectiveness. J. A. M. A. 124:798 (março, 18) 1944.

71. Goodhill, V. - Penicillin treatment of cavernous sinus thrombosis. J. A. M. A. 125:21 (maio, 6) 1944.

72. Nicholson, W. M. e Anderson, W. B. - Penicillin in the treatment of cavernous sinus thrombophlebitis. J. A. M. A. 126:12 (setembro, 2) 1944. 
deixem seqüelas proporcionais ao grau da lesão. Bom resultado foi obtido em neurites do acústico e, ótimo, nos processos gomosos dos ossos cranianos. Stokes e col.44 relataram 182 casos cujos resultados resumiremos. Esses doentes foram observados durante curto período de tempo e medicados por métodos não uniformes. Assim, os resultados apresentados nada mais são que indicações das possibilidades da terapêutica penicilínica no vasto campo da patogenia neuroluética. $O$ material apresentado compreende paralisia geral, tabes dorsalis, atrofia óptica primária, neurossífilis meningovascular, além de outros tipos de sífilis tardia não localizada no sistema nervoso.

\begin{tabular}{|c|c|c|c|c|}
\hline MOLESTIA & RESULTADOS & $C L f_{N I}$ & Icos & \\
\hline $\begin{array}{c}\text { Paralisia } \text { geral simples } \\
(30 \text { casos })\end{array}$ & $\begin{array}{l}\text { melhora de } 75 \% \\
\text { melhora de } 50 \% \\
\text { melhora de } 25 \% \\
\text { nenhuma melhora } \\
\text { piora }\end{array}$ & $\begin{array}{l}\mathrm{em} \\
\mathrm{em} \\
\mathrm{em} \\
\mathrm{em} \\
\mathrm{em}\end{array}$ & $\begin{array}{r}8 \\
5 \\
10 \\
6 \\
1\end{array}$ & $\begin{array}{c}\text { casos } \\
" \\
" \\
\text { caso }\end{array}$ \\
\hline $\begin{array}{c}\text { Paralisia geral em deterioração } \ldots . . \\
(10 \text { casos })\end{array}$ & $\begin{array}{l}\text { melhora de } 75 \% \\
\text { melhora de } 50 \% \\
\text { nenhuma melhora }\end{array}$ & $\begin{array}{l}\text { em } \\
\text { em } \\
\text { em }\end{array}$ & $\begin{array}{l}2 \\
1 \\
7\end{array}$ & $\begin{array}{l}\text { casos } \\
\text { caso } \\
\text { casos }\end{array}$ \\
\hline $\begin{array}{c}\text { Paralisia geral galopante } \ldots \ldots \ldots \cdots \\
\qquad(2 \text { casos })\end{array}$ & falecimento & em & 2 & $n$ \\
\hline Tabes $\underset{(14 \text { casos })}{\operatorname{dor}\left(14 a^{\prime}\right.} \ldots \ldots \ldots \ldots \ldots \ldots$ & $\begin{array}{l}\text { melhora de } 50 \% \\
\text { nenhuma melhora }\end{array}$ & em & $\begin{array}{r}3 \\
11\end{array}$ & $n$ \\
\hline $\begin{array}{c}\text { Atrofia óptica primária } \ldots \ldots \ldots \ldots \cdots \\
(2 \text { casos })\end{array}$ & $\begin{array}{l}\text { cura } \\
\text { melhora de } 50 \% \\
\text { melhora de } 25 \% \\
\text { nenhuma nielhora } \\
\text { piora }\end{array}$ & $\begin{array}{l}\mathrm{em} \\
\mathrm{em} \\
\mathrm{em} \\
\mathrm{em} \\
\mathrm{em}\end{array}$ & $\begin{array}{l}2 \\
1 \\
2 \\
1 \\
1\end{array}$ & $\begin{array}{l}\text { n } \\
\text { caso } \\
\text { casos } \\
\text { caso } \\
n\end{array}$ \\
\hline $\begin{array}{c}\text { Neurossifilis meningovascular } \ldots \ldots \\
(10 \text { casos })\end{array}$ & $\begin{array}{l}\text { melhora de } 75 \% \\
\text { melhora de } 50 \% \\
\text { melhora de } 25 \% \\
\text { nenhuma melhora } \\
\text { piora }\end{array}$ & $\begin{array}{l}\mathrm{em} \\
\mathrm{em} \\
\mathrm{em} \\
\mathrm{em} \\
\mathrm{em}\end{array}$ & $\begin{array}{l}2 \\
2 \\
2 \\
3 \\
1\end{array}$ & $\begin{array}{c}\text { casos } \\
" \\
" \\
\text { caso }\end{array}$ \\
\hline
\end{tabular}

Sôbre as reações serológicas o efeito foi o seguinte: a) no sangue: efeito de Herxheimer em $20 \%$ dos casos. melhora mas não negativação em $34 \%$; negativação em $10 \%$; melhora temporária em $13 \%$ e sem alteração $23 \%$. b) No líqüido cefalorraquidiano:

\begin{tabular}{|c|c|c|c|c|c|}
\hline & Melhora: & $a$ & $b$ & $c$ & $d$ \\
\hline $\begin{array}{l}\text { Grau 1: } \\
\text { Grau 2: } \\
\text { Grau 3: } \\
\text { Grau 4: } \\
\text { Grau 5: }\end{array}$ & 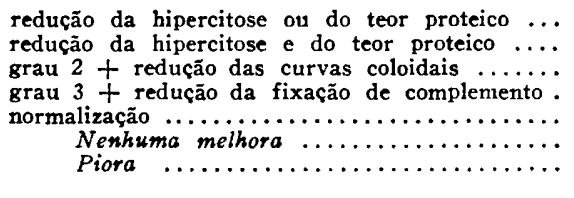 & $\begin{array}{r}6 \\
19 \\
4 \\
4 \\
0 \\
5 \\
4\end{array}$ & $\begin{array}{l}4 \\
2 \\
4 \\
7 \\
0 \\
5\end{array}$ & $\begin{array}{l}7 \\
5 \\
6 \\
9 \\
1 \\
6 \\
6\end{array}$ & $\begin{array}{r}17 \\
26 \\
14 \\
20 \\
1 \\
16 \\
13\end{array}$ \\
\hline
\end{tabular}

a) Paralisia geral progressiva e taboparalisia (42 casos); b) Tabes e sifilis meningovascular (25 casos); c) sífilis assintomática (40 casos); d) total (107 casos). 


\section{CAUSAS DE INSUCESSO DA PENICILINOTERAPIA}

Devido à grande publicidade feita em tôrno da penicilina, o poro e mesmo alguns profissionais adquiriram um conceito errôneo a respeito dêsse medicamento, julgando-o eficaz contra tôdas as moléstias infecciosas. ${ }^{73} \mathrm{O}$ uso da penicilina deve ser restringido a infecções produzidas pelos germes sensíveis à sua ação, já referidios anteriormente. Entre êstes, existem cepas insensíveis, germes penicilino-resistentes e germes residuais. Em razão dêstes fatos, deve-se fazer testes de laboratório capazes de dosar a sensibilidade do germe produtor da enfermidade cuja evolução não se faz favoràvelmente, apesar da terapêutica penicilínica.

Existe a possibilidade excepcional da terapêutica falir frente a uma infecção inusualmente grave. Outras infecções, por propriedades diversas, são capazes de dificultar a ação da penicilina. mesmo quando os germes que as produzem sejam sensíveis in vitro. E o caso da meningite pneumocócica, em que a tendência para formar aracnoidite adesiva, encefalite e denso exsudato gelatinoso impede o medicamento de atuar no ponto da infecção. E porisso que se usam em conjunto as vias ventricular, suboccipital e lombar, para conseguir a difusão do medicamento.

Contra as infecções graves e aquelas cujo caráter dificulta a ação da penicilina, impõe-se a medicação associada. Conhecemos a ação sinérgica das sulfonamidas e dos soros específicos e as vantagens resultantes da drenagem das coleções purulentas.

Além da falência da penicilina pelo seu uso contra germe insensível ou em virtude do caráter inusualmente grave da infecção e dos caraterísticos próprios da moléstia, ou por faltar medicamentos associados, existe a possibilidade de sua ineficiência correr por conta das condições físicas e etárias do paciente. A penicilina ¿ bacteriostática e não bacteriolítica; por êste motivo é necessário que os tecidos orgânicos reajam controlando os germes patogênicos; em pessoas de idade avançada ou naquelas com baixa vitalidade, o organismo torna-se incapaz de combater a infecção, pois seus tecidos idosos ou sèriamente lesados não podem desempenhar seu papel antibacteriano.

Rua Vitorino Carmilo 453, casa 6.

73. Penicillin dosage (Editorial) Lancet 2:508 (outubro, 14) 1944.

- Bloomfield, A. L. e outros. - A study of penicillin failures. J. A. M. A. 126:685 (novembro, 11) 1944 . 